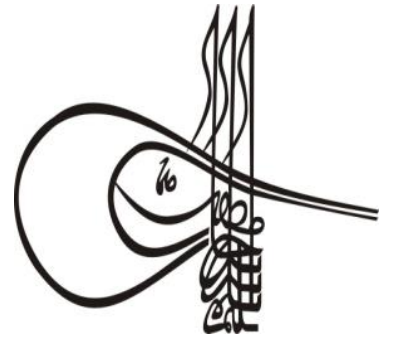

Received/Geliș: 16.03.2019

\author{
Turkíslo Studies \\ Historical Analysis \\ Volume 14 Issue 2, 2019, p. 397-411 \\ DOI: 10.29228/TurkishStudies.22909 \\ ISSN: 2667-5552 \\ Skopje/MACEDONIA-Ankara/TURKEY
}

Research Article / Araştırma Makalesi

Article Info/Makale Bilgisi

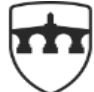

INTERNATIONAL BALKAN UNIVERSITY

EXCELLENCE FOR THE FUTURE IBU.EDU.MK

$\checkmark$ Accepted/Kabul: 10.06.2019

Gor Report Dates/Rapor Tarihleri: Referee 1 (17.04.2019)-Referee 2 (16.05.2019)

This article was checked by iThenticate.

\title{
BÜYÜK SELÇUKLU DEVLETI'NİN OĞUZLAR-TÜRKMENLERE KARŞI TAKİP ETTİĞİ SIYYASET (BAŞLANGIÇTAN YIKILIŞA KADAR)
}

\author{
Ayhan Afşın ÜNAL*
}

\begin{abstract}
öz
Büyük Selçuklu Devleti'nin kurulmasından sonra, Orta Asya'dan gelen Oğuzlar Selçuklu idarecileri tarafından, İslam dininin gaza ve cihat emri gereği, gayr-i müslimlerle mücadele sahası olan daha Batı'daki Bizans sınır bölgelerine gönderiliyorlardı. Böylece hem Türkmenler için hayati önem taşıan yaylak-kışlak problemine çözüm bulunuyor hem de yeni topraklar elde ediliyordu. Bu uygulama Büyük Selçuklu Devleti'nin güçlenmesinde etkili olmuş ise de Selçuklu idarecileri ile irkdaşlarının arasını da açmıştır. Çünkü daha devletin kuruluşu, yani Dandanakan savaşından hemen sonra, Selçuklular içinde yaşadıkları sosyal çevrenini de tesiriyle, idareleri altında yaşayan yerleşik halkın etkisi altında kalmışlardır. Böylece kurdukları devlet, kurucusu olan OğuzlarTürkmenlerden sosyal, iktisadi ve idari bakımlardan uzaklaşarak, tedricen yerlessik halkın devleti haline gelmiștir. Sivil ve askeri idarenin teşkilinde Gazneli Devleti'nden iltica eden kumandanlar Selçuklu askeri kadrosuna, memurlar da Selçuklu Devleti'nin sivil kadrosunda görev almak suretiyle bahsi geçen devletin kuruluşunda her türlü sıkıntıyı çeken, atlı-göçebe kültürün temsilcisi Oğuzlar-Türkmenler ikinci plana itilmişlerdir. Zamanla gûlam sistemine göre yetişmiş mülteci kumandanlar ve sivil idarede görev alan İranlı memurlar, Oğuzları küçümsemeye hatta tahrik etmeye başlamışlar, bu uygulama Selçuklu Devletinde "Türkmenler meselesini" doğurmuştur. XI. Yüzyıl için o çağın modası olarak kabul edilen bu değișiklikler, Türk sosyal ve siyasi nizamının yıkılmasında etkili olmuştur. Hemen her çağda ortaya çıkan sosyo-kültürel akımlar cemiyetlerin sarsılmasina ve hatta ani değişiklikler bazı buhranların doğmasında temel faktör olabilmektedir.
\end{abstract}


Anahtar Kelimeler: Büyük Selçuklu Devleti, Oğuzlar-Türkmenler, devlet, idare, politika.

\title{
POLITICS THAT THE GREAT SELCUK STATE IS FOLLOWING THE OGHUZES AND THE TURKMENS (FROM START TO FALL)
}

\begin{abstract}
After the establishment of the Great Seljuk State, the Oghuzes from Central Asia were sent by the Seljuk rulers to the Byzantine border regions in the West, which was the area of the fight against non-Muslims, because of the Islam and the order of jihad. Thus, the solution to the problem of spring-wintering which is of vital importance for Turkmens and new lands were obtained. This practice has been instrumental in the strengthening of the Great Seljuk State, but it has also opened the gap between the Seljuk rulers and their racemates. Because the foundation of the state, that is, immediately after the Dandanakan war, the Seljuks were under the influence of the inhabitants living under their administration with the effect of their social environment. Thus, the state they established has gradually moved away from the social, economic and administrative aspects of the founder of the Oghuzes-Turkmens. In the formation of the civil and military administration, the commanders of the Gazneli State were taken to the Seljuk military cadres, and the civil servants, and the Oghuz-Turkmens, who were the representatives of the equestrian-nomadic culture, who were suffering from all kinds of problems in the establishment of the state by being employed in the civilian staff of the Seljuk State, were pushed to the second plan. In time, according to the gulam system, trained refugee commanders and Iranian civil servants in the civil administration started to underestimate Oghuz and even provoke them. This practice gave birth to the Turkmen issue and in the Seljuk State. XI. These changes, which were accepted as the fashion of the era for the century, were effective in the destruction of the Turkish social and political order. The socio-cultural currents that have emerged in almost every age can be the main factor in the shaking of societies and even sudden changes may be the main factor in the emergence of some crises.
\end{abstract}

\section{STRUCTURED ABSTRACT}

The Oghuz Turks, the Turkish-Islamic history, the initiation of a new political process, the founder of the Great Seljuk State, the Turkish community in the history of Turkish-Islamic events, which will be considered a revolution. The Oghuz Turks played an important role in the expansion and expansion of the borders of this state. There are many opinions about the origin, structure and meaning of the Turkmen name. This word, which is used for people living in Turkmenistan in the narrow sense, is generally used for all Oghuz Turks. They accept themselves as some of the nomadic Turkmen in Turkey, is also known that such naming. IX. And in the X. Centuries, Muslim Arabs and Persians called 
them ve Turkmen in order to distinguish the Muslims from the nonMuslims by accepting Islam.

The Turkmen are considered to be politically engaged with the Seljuk State on the stage of history. Yabgu, who was at the head of the Oghuz, marched on the Muslim Turkmens. Seljuk Bey, who would later establish a state bearing his own name, fought against Yabgu and defended the Muslim Oghuz, who became known as Turkmen. According to Kasgarli Mahmut, the rulers of the Oguz tribe are of Kinık tribe. According to Faruk Sumer, XI. Turkmen Oguz called themselves century onwards, Turkey with Iran, Turkey, Azerbaijan, Iraq and Turkmenistan are the ancestors of the Turks. The Oghuz people, who were also the founder of Seljuk and Ottoman dynasties, lived in the secrets of Sir-Derya (Seyhun) and Oghuz-Yabgu State in the north of the Seljuk family in the early stages of the X-Century. a large part of the traditional equestriannomadic life style according to the name they continue to live.

In the birth and development of the equestrian-nomadic culture, the geographical location experienced was of course influential. The Turks generally maintained the equestrian-nomadic lifestyle in East Turkestan and Asia, which were suitable for this lifestyle. When they found a suitable ground for settlement in Western Turkestan, Azerbaijan, Anatolia and other Turkish Dormitories, they settled in partial settlements or settled in urban life. As a result of this settlement, the states they established had a longer life span and had the opportunity to reveal the elements of material culture besides spiritual cultures. However, it is important to note that the Turks, who have settled, have lost their political and cultural assets over time if they are not supplemented by migration from Motherland. After Turkish settlements came to China, India and the North of the Black Sea and came to Eastern Europe and the Balkans, they lost their self over time with the influence of foreign cultures. Because no matter how effective and superior a society is in terms of culture and political power, if it is less in number than the people it lives with, then it is doomed to disappear. However, the Turkish-Oghuz tribes, who maintained the arasinda horse-riding nomadic lifestyle $\mathrm{O}$, were not lost among the domestic elements even though they were few in number because they could preserve their ego and dynamism against foreign cultural influences. When the political events in our history were examined, although the societies which had settled against the foreign invasions immediately obeyed the forces they did not resist, they were active because they could easily change their positions against the oppressive Turkmen element oppression with their tents and sheep and fate flocks and their tents.

In almost every period of Turkish history, there was alarında settled-nomadic esi struggle in the establishment and demolition of Turkish States. Almost all of the Turkish States established in Western Turkestan and Near East have been active, military, and financially representative of the 'equestrian-nomadic culture. These political organizations founded in the mentioned regions gained a centralist character from their organizations for a while. This change in the structure, the founder of the state, and the neglect of the Oghuz-Turkmen tribes, as the main element on which it was based, led to the emergence of new institutions (military, financial and administrative) that are 
required by the age. Thus, after some time in the administrative and military levels of the newly established state in gûlam ibi element had a say and the main element on which the state was based was neglected. This conflict is an important issue in almost all of the resident Turkish States. It can be said that this humor must be sought in the establishment and dissolution of the Turkish states throughout history.

The Great Seljuk State was founded by the sons and grandchildren of Seljuk Bey, a member of the Kinık tribe of the Oghuz Turks. The foundation of Seljuk and his sons was the Oghuz Turks. Seljuk lords, from the first half of the X. Century to establish their own state before the Karahanllarla Maveraünnehirlerle, then in the tough struggle against the Ghaznavid Gazars. During this struggle, the armies of the Seljuks consisted entirely of Turkmen horsemen. For more than a century until the foundation of the Seljuk State, the Turkmen, who had suffered a thousand and a thousand hardship as an asylum seeker, were liquidated by the Seljuk beys after the 1040 Dandanakan Victory. Instead of Turkmen horsemen, a new army consisting of free Turks, who were trained according to the sistemi gûlam system iştiril by the same gentlemen, was established by the same gentlemen. Therefore, the Turkmen masses who settled in the Seljuks were settled in places such as Western Iran, Northern Iraq and Azerbaijan and settled near the ends. The reason for this liquidation was the fact that in Turkmen masses the stature of the boy was very strong and that they were more obedient to their lords than the Seljuks. The Seljuks also regarded this situation as dangerous for their rulers and pursued a policy of removing them from the center of the state. For this reason, they showed Anatolia as the target and country, and encouraged them to go here. As a natural result of this policy, an important historical event and phenomenon has occurred in Turkishness, such as the conquest of Anatolia and its becoming a Turkish homeland. All Turkmens did not participate in the conquest of Anatolia. Some of them remained in Seljuk country (Iran) and continued their negative attitudes towards Seljuk Bey's administration and policies. These Turkmens have shown a great reaction against the rapidization of the state, especially from being a Turkish state. They have shown this reaction frequently, supporting and supporting them, behind every dynasty member who has taken action to seize power against the legitimate administration. However, these dynasty members have not succeeded in any of the power struggles they have taken, despite the full support of the Turkmen. In other words, the Turkmens could not change the Seljuk rule in accordance with their own desires and purposes. In addition, the Turkmen masses, from time to time, have rebelled against the legitimate administration due to the heavy tax demands of Seljuk beys and their neglected policies.

The greatest result of the Oguz rebellion was that Sencer was captured by the Oghuzes and thus the de facto end of the Great Seljuk Empire. It is seen that Oghuzs, in order to preserve the existing order and to prevent external intervention, found Sencer suitable for protecting and showing him as ruler. The neglect of the Seljuk sultans, who were indifferent to their own people, forced the reign of the Oghuz Turks, the founder and principal owner of the state. 


\section{Result}

The Great Seljuk State was the fourth largest empire after the Huns, Gokturks and Uighurs, which the Turks had established in history, and the first great empire of the Islamic era. Seljuk Bey and his family, who founded this state and the state, leaned his back to his racemates, namely the Oghuzes-Turkmens since their foundation, struggled with them, and with their help, they conquered vast geographies and established their state. But the political, administrative and social developments, conditions and requirements brought about by the progress towards the west into the Islamic world have forced them to go into different practices in the state administration, and with the expansion of the state they have established, the bureaucracy has begun to take place increasingly in the administration. This situation led to the fact that the Oghuzes-Turkmens, who were the founding members of the state, remained exclusively in the military field and were removed from the state administration, they fell into the second plan, and the Iranian Persian bureaucrats became more active with Nizamü askerl-property. The Oghuz-Turkmen tribes, who were annoyed by the state and the sultans they established, were dismissed and dismissed from the government, showed that they had rebelled and eventually demolished the state they had established.

Keywords: The Great Seljuks State, The Oghusez-Turkomans, state, administration, politics.

\section{Giriş}

Oğuzlar, Türk - İslam tarihi içinde, yeni bir siyasi süreç başlatan Büyük Selçuklu Devleti’nin kurucusu, Türk-İslam tarihinde devrim sayılacak olayların öncüsü olan Türk topluluğudur. Oğuzlar, kurmuş oldukları bu devletin hem sınırlarını genişletmede ve hem de yıkılışında büyük bir rol oynamışlardır. Türkmen adının kökeni, yapısı ve anlamı hakkında birçok farklı görüş bulunmaktadır. Bugün dar anlamda Türkmenistan'da yaşayanlar için kullanılan bu sözcük, genel anlamda bütün Oğuz Türkleri için de kullanılmaktadır. Türkiye'de bazı Yörüklerin kendilerini Türkmen olarak kabul ettikleri, böyle adlandırdıkları da bilinmektedir. IX. Ve X. Yüzyıllarda Müslüman Araplar ve Farslar, Oğuzların İslamiyeti kabul edip Müslüman olanlarını, olmayanlardan ayırmak için onlara "Türkmen" demişlerdir.

Türkmen adının en başta Divanü Lûgat-it Türk’te Kaşgarlı Mahmut'un “Bunlar Oğuzlardır. Bunlara Türkmen denilmesinde bir hikâye vardır (Kaşgarlı Mahmud, s. 412)" sözünde geçtiği bilinmektedir. Kaşgarlı'nın bahsettiği hikâyeye göre Balasagun'daki bir Türk hakanı doğuya çekilmiş ve orada yalnızca 22 kişi kalmıştır. Sonra 24 kişi olan bu insanlar üzerine saldıran Büyük İskender (Zülkarneyn), onların üzerlerinde Türk belgeleri bulunca onları Farsça -Türk’e benzeyen- anlamına gelen "Türkmanend" biçiminde adlandırmıştır.

Türkmen adının "Türkiman" (iman etmiş Türk) adından geldiğini İlhanlı tarihçisi Reşideddin Camü't-Tevarih adlı eserinde yazmıştır (Reşidü'd-din Fazlullah, 2016, s. 15). Necip Asım bu adın adam anlamına gelen "+man" ekinden ortaya çıktığını ve "Türk eri" anlamında kullanıldığını savunmuştur (Asım, 2015, s. 54). A. Vámbéry “Türk men” (ben Türk'üm) sözünün kalıplaşması ile Türkmen adının ortaya çıktığını ileri sürmüştür (Armenius Vambery, 2004, s. 47).

Faruk Sümer, Müslümanlığı kabul eden Türklerin diğer Türk boylarından farkını belirtmek için Türkmen adını kullandıklarını ileri sürmüştür. Bu fikir, birçok bilim adamı tarafından kabul görmüştür. Fakat Jean Deny Türkçede “+man” ekinin büyüklük, fazlalık, üstünlük, abartma anlamı taşıdığını ve 
“Türk+man" adının (koyu Türk, saf Türk) anlamına geldiğini ifade eden görüşü (Deny, 2012, s. 17), Türklük bilimi dünyasında en çok kabul gören görüş olmuştur.

Türkmenler, bozkır yaşamının bir gereği olarak göçer yaşam süren bir Türk boyudur. Teke, Yomut, Ersarı, Sarık, Salır, Gökleñ ve Çovdur gibi boylardan oluşan Türkmenler, Oğuz soylu Türkler'dendir.

Türkmenler siyasi olarak Selçuklu Devleti’yle tarih sahnesine çıkmış sayılırlar. Oğuzların başında bulunan Yabgu, müslüman Türkmenler'in üzerine yürümüștür. Sonraları kendi adını taşıyan bir devlet kuracak olan Selçuk Bey, Yabguya karşı mücadele etmiş ve Türkmen adıyla anılmaya başlayan müslüman Oğuzları korumuştur (Rızayev, 2010, s. 213-222).

Kaşgarlı Mahmut'a göre, Oğuz kabilesini idare edenler, Kınık boyundandır. Faruk Sümer'e göre, XI. yüzyıldan itibaren kendilerine Türkmen denilen Oğuzlar, Türkiye Türkleri ile İran, Azerbaycan, Irak ve Türkmenistan Türklerinin atalarıdır. Selçuklu ve Osmanlı hanedanlarının da kurucusu olan Oğuzlar, X. Yüzyılın başlarında, Selçuklu ailesinin tarih sahnesinde ilk defa çıktığı dönemlerde Sır-Derya (Seyhun) boyları ile onun kuzeyindeki bozkırlarda Oğuz-Yabgu Devleti'nin sahip olduğu sahada yaşarlarken onlardan ancak bir bölümü şehirlerde oturuyordu, büyük bir kısmı geleneksel atl1-göçebe veya konar-göçer diye de isimlendirdiğimiz hayat tarzına göre hayatlarını devam ettiriyorlardı (Sümer, 1992, s. 46-67), (Agacanov, 2013, s. 141-146)

Selçuklu Devleti ve Oğuz boyları arasındaki münasebetlerin detaylarına girmeden önce OğuzTürkmen boylarının geleneksel hayat tarzı olan atlı göçebe hayat tarzından biraz bahsetmek, bilgi vermek konunun daha iyi anlaşılması açısından faydalı olacaktır. Zira Türk kavimlerinin ekonomik yapısının esasını teşkil eden "atlı-göçebe hayat tarzı", bugün Anadolu yaylalarında Oğuz-Türkmen boylarından gelen aşiretlerimiz tarafından temsil edilmektedir.

Atl1-göçebe kültürün doğmasında ve gelişmesinde, üzerinde yaşanılan coğrafi mekân elbette etkili olmuştur. Türkler, umumiyetle Doğu Türkistan ve Asya'nın bu hayat tarzına elverişli yörelerinde atl-göçebe hayat tarzını sürdürmüşlerdir; Batı Türkistan, Azerbaycan, Anadolu ve diğer Türk Yurtları'nda yerleşmek için uygun zemin buldukları zaman kısmi yerleşme (konar-göçer) veya tamamen şehir hayatına geçtiler. Bu yerleşmenin sonucu olarak da kurdukları devletler daha uzun ömürlü olmuş, manevi kültürler yanında maddi kültür unsurlarını ortaya koyma imkânı bulmuşlardır. Ancak şurasını önemle belirtmek lazımdır ki, yerleşik hayata geçen Türkler, Anayurt'tan göçlerle takviye edilmedikleri takdirde zamanla siyasi ve kültür varlıklarını kaybetmişlerdir. Çin'e, Hindistan'a ve Karadeniz'in Kuzey'inden geçerek Doğu Avrupa ve Balkanlar'a gelen Türk Boyları yerleşik hayata geçtikten sonra yabanc1 kültürlerin de tesiriyle zamanla benliklerini kaybettiler. Çünkü bir toplum kültür ve siyasi güç bakımından ne kadar etkili ve üstün olursa olsun, sayı bakımından birlikte yaşadığı insanlara nazaran az ise, o zaman, kaybolmaya mahkûmdur. Oysaki "atlı göçebe hayat tarzını" devam ettiren Türk-Oğuz Boyları, yabancı kültür tesirlerine karşı benliklerini ve dinamizmlerini muhafaza edebildikleri için, sayıca az olsalar bile yerli unsurlar arasında kaybolmamışlardır. Tarihimizdeki siyasi olaylar incelendiği zaman, yabancı istilalara karşı yerleşik hayata geçmiş olan toplumlar karşı koymadıkları güçlere hemen itaat ettikleri halde, servetleri koyun ve yılkı sürüleri, evleri çadırları olan atlı-göçebe Türkmen unsuru baskılar karşısında kolayca yer değiştirebildikleri için etkin olmuşlar ve kültür yapılarını koruyabilmişlerdir (Yinanç, 2009, s. 41-42).

Türk tarihinin hemen her döneminde, Türk Devletleri'nin kuruluş ve yıkılmalarında "yerleşikgöçebe" çekişmesi söz konusu olmuştur. Batı Türkistan ve Yakın Doğu'da kurulan Türk Devletleri'nin hemen hepsi, etkin, askeri ve mali yönden "atlı-göçebe kültürün temsilcileri olmuşlardır. Bahsi geçen yörelerde kurulan bu siyasi teşekküller kuruluşlarından bir müddet sonra merkeziyetçi bir karakter kazanmışlardır. İşte bu yapı değişikliği, yani devletin kurucusu ve dayandığı esas unsur olan OğuzTürkmen boylarının ihmali, çağın gereği olan yeni müesseselerin (askeri, mali ve idari) doğmasına sebep 
olmuştur. Böylece yeni kurulan devletin idari ve askeri kademelerinde bir müddet sonra "gûlam" unsuru söz sahibi olmuş, devletin dayandığı esas unsur Oğuz-Türkmen boyları ihmal edilmiştir. Yerleşik Türk Devletleri'nin hemen hepsinde önemli bir mesele olarak bu anlaşmazlık karşımıza çıkmaktadır (Yuvalı, 1992, s. 5-12), (Nizam'ül-mülk, 2009, s. 136). Denilebilir ki, tarih boyunca Türk Devletlerinin kurulmalarında ve dağılmalarında bu espri aranmalıdır.

Türk Devlet mefhumunda "halk" ile "vatan" yani toprak ile insan iki önemli unsurdur. Vatansız bir devlet düşünülemediği için uğruna can verilir. Bir aile için "ev" ne ise, devlet için de "vatan" aynı şeydir. Bu anlayışın kökleri Türk tarihi kadar eski ve oldukça sağlam bir dünya görüşüne dayanıyordu. Türk milletinin tarih boyunca varlığını korumasının en önemli sebeplerinden biriside "Türk devlet geleneği" dir. Aynı zaman içerisinde farklı coğrafyalarda kurulmuş olan devletlere Türk devleti diyebilmemiz bazı kriterlere bağlıdır. Bu kriterlerin en önemlisi "Türk devlet geleneği" dir. Devletin dayandığı iki önemli unsura, üçüncü olarak "töre"yi ve dördüncü olarak da "kağan"1 ilave edebiliriz (Ögel, Türk Kültürünün Gelişme Çağları, 1971, s. 52).

Türk tarihinin kesiksiz bir biçimde devam eden akışını daha iyi anlayabilmek için, Türk aile yapısını ve aile fertlerinin aile içindeki fonksiyonlarını tespit etmek gerekir. Türk inanışına göre aile, devletin küçük bir modeli ve sosyal yapısının çekirdeğidir. Ailede başlayan bozulma toplumu ve dolayısıyla devleti etkiler. Üç Kıt'a üzerinde kurulmuş olan Türk Devletlerinin hemen hepsinde "aile" ve "devlet geleneği” önemli yer işgal etmiştir. Türk olma ve Türk kalma özelliği olarak gördügümüz bu iki mefhumdan birisi olan "Türk devlet geleneği" her kurulan yeni devlette kaybolmamış, devlet dağılmış olsa bile "devletçi boy" ve bu boy içendeki aile" varlığını sürdürmüş, firsat bulduğu zaman ortaya çıkarak yeni devlet kurmuştur (Ögel, Türklerde Devlet Anlayışı (XIII. Yüzyıl Sonlarına Kadar), 1982, s. XIII). Bu yüzden bir devlete Türk Devleti diyebilmemiz için bu özelliği yani "Türk devlet geleneği”"ne sahip olması gerekir._Devletin dayandığı esas unsurlardan birisi olan "töre", örf-adet hukuku olup, günümüzde halk arasında "yol yordam” olarak bilinmektedir. İslam öncesi Türk Devletleri iki sosyal yapı üzerine bina edilmişti. Bunlar aile ve ordu gibi varlıkları çok eskilere kadar giden iki önemli sosyal kurumdur. Aile içinde baba, boy içinde bey ve devlet içinde de kağanın yeri tespit edildiği zaman bu sosyal yapı anlaşılmış olur (Ögel, Türklerde Devlet Anlayışı (XIII. Yüzyıl Sonlarına Kadar), 1982, s. 337), (Agacanov, 2013, s. 153-167). Tarihi devirlerde kurulan Türk devletlerinin tebaasını oluşturan bu sosyal yapıda aile toplumun çekirdeği ve temel taşıdır. Aileler birleşerek oba, uruk, aşiret dediğimiz birimi oluşturur, aşiretler birleşerek boyları meydana getirirler ve en nihayet boylar birleşerek budunu yani milleti teşkil ederler. Budun kelimesi bazen milletin bir kısmını da ifade edebilir, mesela Orhun Kitabelerinde geçen "Dokuz Oğuz Budunu” söyleyişinde olduğu gibi. Bey ile halk arasında yazılı olmayan, töre gereği bir antlaşma vardır. Töre, toplumun esas idi. Devletlerin yıkılması, aşiretlerin dağılmasının esas sebebi, töreden uzaklaşmadır. Bey ile halk arasındaki dayanışmaya ve anlaşmaya Türkler "tüz" düz olma derler. Boy beyi ile kağan arasında düşünce ve görev bakımından pek fark yoktur (Ögel, Türklerde Devlet Anlayışı (XIII. Yüzyıl Sonlarına Kadar), 1982, s. 300-302), sadece görevin hacmi farklıdır.

Türk kavimlerinin, İslam dairesine girmeleri ve bu yüce dinin mensubu olmaları ile yerleşik hayata geçişleri daha da hızlanmıştır. Önce Batı Türkistan, Azerbaycan, İran, Mezopotamya ve nihayet Anadolu'nun Türk göçlerine sahne olmasıyla, buralarda kurulan Türk devletlerini meşgul eden yeni bir mesele ortaya çıkacaktır: "Türkmenler Meselesi” (Kafesoğlu, Eylül 2014,, s. 82). İran, Azerbaycan ve Anadolu'nun fethinde öncü rolü oynayan atl-göçebe Oğuz-Türkmen unsuru, bahsi geçen yörelerde kurulan Türk devletlerinde esas unsur ve devletin kurucusu olmuşlardır. Ancak devletlerin kurulmasından sonra, bünyesinde meydana gelen idari, askeri ve sosyal değişmeler o çağın gereği sayılsa bile, devletlerin asıl sahibi olan atl1-göçebe unsuru rahatsız etmiştir. Bu değişmeyi Yakın Doğu'nun bahsi geçen çağdaki en güçlü temsilcisi olan Büyük Selçuklu Devleti'nde açık bir şekilde görmek mümkündür. 


\section{Büyük Selçuklu Devleti ve Oğuzlar-Türkmenler}

Büyük Selçuklu Devleti, Oğuzların Kınık boyuna mensup olan Selçuk Bey’in oğul ve torunları tarafından kurulmuştur. Kuruluş döneminde Selçuk ve oğullarının yegâne dayanağı Oğuz Türkleri idi. Selçuklu beyleri, X. Yüzyılın ilk yarısından itibaren kendi devletlerini kurmak için önce Maveraünnehir'de Karahanlılarla, sonra da Horasan'da Gaznelilere karşı çetin bir mücadeleye girmişlerdir. $\mathrm{Bu}$ mücadele sırasında Selçuklu beylerinin orduları tamamen Türkmen atlılarından oluşmaktaydı. Selçuklu Devleti kuruluncaya kadar bir asırdan fazla bir süre, yersiz ve yurtsuz bir halde, sı ğınmacı olarak bin bir sıkıntı çekmiș olan Türkmenler, 1040 Dandanakan Zaferi'nden sonra Selçuklu beyleri tarafından tasfiye edilmiştir. Türkmen atlılarının yerine de yine aynı beyler tarafından Gazneliler örnek alınarak "gûlam sistemi" ne göre yetiştirilmiş hür Türklerden oluşan yeni bir ordu kurulmuştur. Bunun üzerine Selçuklu beylerine küsen Türkmen kitleleri Batı İran, Kuzey Irak ve Azerbaycan gibi uçlara ve uçlara yakın yerlere gelip yerleşmişlerdir. Bu tasfiyenin sebebi ise, Türkmen kitlelerinde boy anlayışının çok kuvvetli olması ve onların Selçuklu beylerinden çok kendi beylerine itaat ve bağlılık göstermeleriydi. Selçuklu beyleri de kendi iktidarları için bu durumu tehlikeli görmüşler ve onları daime devletin merkezinden uzaklaştırma politikası gütmüşlerdir. Bunun için onlara hedef ve ülke olarak Anadolu'yu göstermişler, onların buraya gitmelerini teşvik etmişlerdir. Bu politikanın doğal sonucu olarak da Anadolu'nun fethi ve Türk vatanı haline gelmesi gibi Türklük bakımından son derece önemli bir tarihi olay ve olgu meydana gelmiştir. Türkmenlerin hepsi Anadolu'nun fethine katılmamıştır. Bunların bir kısmı Selçuklu ülkesinde (İran) kalarak, Selçuklu Beylerinin idare anlayışlarına ve politikalarına karşı olumsuz tavırlarını sürdürmüşlerdir. Bu Türkmenler devletin özellikle bir Türk devleti olmaktan çıkartılıp hızla Farslılaştırılmasına karşı büyük bir tepki ortaya koymuşlardır. Onlar özellikle meşru idareye karşı iktidarı ele geçirmek için harekete geçen her hanedan üyesinin arkasında topluca yer alıp, onlara destek vererek, bu tepkilerini sık sık göstermişlerdir. Fakat bu hanedan üyeleri, Türkmenlerin tam desteğini almalarına rağmen giriştikleri iktidar mücadelelerinin hiçbirinde başarıya ulaşamamışlardır. Başka bir deyişle Türkmenler kendi arzu ve gayelerine uygun olarak Selçuklu iktidarını değiştirememişlerdir. Ayrıca Türkmen kitleleri, Selçuklu beylerinin ağır vergi talepleri ve kendilerini ihmal eden politikaları yüzünden de meşru idareye karşı zaman zaman isyan hareketlerinde bulunmuşlardır. Mesela Horasan'da meydana gelen oğuz İsyanı (1153) ve Anadolu'da ortaya çıkan Babailer isyanı (1243) bunların en önemlileridir (Koca, 2011, s. 4-5).

Devletin kuruluşu sırasında gece uyumadan, gündüz dinlenmeden, aç-susuz Tuğrul ve Çağrı Beylerin yanında devletin kurulması için mücadele eden Oğuzlar-Türkmenler ve onların irsi beyleri, Selçuklu Devleti'nin kurulmasından sonra geri plana itilmişlerdir. Bu yüzden daha Tuğrul Alparslan ve Melikşah zamanlarında görülen şehzade isyanları sırasında isyancı Selçuklu Şehzadelerinin en büyük desteği Oğuzlar-Türkmenler olmuştur (Köymen, 1993, s. 158-167).

Büyük Selçuklu Devleti İçinde Oğuzlar

İslamiyet'i kabul edip, Selçuklu Devleti'ni kurduktan sonraki süreçte, Oğuzları üç kategoride inceleyebiliriz.

a- Yerleşik hayata geçen Oğuzlar. Bunlara Selçuklu Türkü de denilmekteydi. Bunlar, yerleşik hayata geçip tarımla uğraşmakta idiler. Selçuklu Devleti'nin yıkılışında bunlar yerleşik olmayan ırkdaşlarından çok zarar gördüler. Göçebe Oğuzlar, yerleşik hayata geçen urkdaşlarına, Türklüklerini, gelenek göreneklerini kaybedip İranlılaştıkları gerekçesi ile kin tutuyorlardı. Hatta Selçuklu Devleti'nin yıkılışında büyük etkisi olan son isyanlarında bu ırkdaşlarının mallarını yağma edip talan etmişlerdi.

b- İkinci kategoride ise İslamiyet'i kabul etmeyip yerleşik hayata geçmeyen Oğuzlar bulunuyordu. Bunlar, Karahıtaylar'a karşı devletin doğu sınır boyunu oluşturuyordu. Doğudan gelebilecek her türlü tehlikeye karşı tampon görevi görüyorlardı. Fakat yanlış politikalar neticesinde bunlara önem verilmedi. Sıkışıp kaldıkları bölgede sürülerine otlak bulamadılar. Oysa onların katında 
devlet baba idi. Velayet-i pederâne görevini üstlenmesi gerekiyordu. Devletin kutsallı̆̆, kuta sahip olması ancak bu şekilde olabilirdi. Devlet, onların sürülerine otlak bulmak zorunda idi. Yine eski Türk geleneklerinde vergi yoktu. Onlara göre, İran etkisinde kalan Selçuklu Devleti, bunların üzerine ağır vergiler yükleyip Oğuzları da yerleşik halk ile aynı kategoride görmek istediler. Oysa buradaki Oğuzlar, iç işlerinde bağımsızdılar. Kendilerini Selçukluya bağlı Yabgu devleti halinde görüyorlardı. Büyük Selçuklu Devleti, daha sonra Müslüman olmayan bu Oğuzları orduya da almadı. Buna karşılık, memlük sistemiyle yetişen kişileri hem devlet kademelerine hem de ordu kademelerine getirmeye başladı. Bu da Oğuzlar'ın devlete karşı kin duymasına sebep oluyordu. Bütün bunların etkisi ile Oğuzlar, devletin toprağa bağlı iktâ askerlerine karşı göçebe olmayı tercih ettiler. Eski Türk inancına dinine mensup olan bu Oğuzların bir kısmı, daha sonra Bâtınilik mezhebini benimsedi. Tarih kayıtlarında Oğuzların Bâtınilere yardımları ile ilgili bilgiler mevcuttur. Bu Oğuzlar, git gide devlete karşı yıkıcı bir güç oluşturmaya başladılar. Katvan savaşından sonra bu güçlerini ortaya koyup devletin yıkılmasında rol oynadilar.

c- Üçüncü kategoride ise İslâmiyeti kabul edip yerleşik hayata geçmeyen Oğuzlar yer almaktadır. Bunlar, Türklüklerinden hiçbir şey kaybetmemişlerdi. Bunlar Yabgulu Türkmenleri ile aynı kategoride bulunuyorlardı. Bu Oğuzlar, devletin İranlılaşmasından rahatsız olmuşlardı. Hanedan isyanlarında göçebe yönü ağır basan devlet kurma amacından ayrılmadılar (Demir, 2004, s. 153-155) ${ }^{1}$.

Devletin kurulmasından sonra, Anayurt'tan bölük bölük gelen Oğuzlar Selçuklu idarecileri tarafından, İslam dininin gaza ve cihat emri gereği, gayr-i müslimlerle mücadele sahası olan daha Batı'daki Bizans sınır bölgelerine gönderiliyorlardı. Böylece hem Türkmenler için hayati önem taşıyan yaylak-kışlak problemine çözüm bulunuyor hem de yeni topraklar elde ediliyordu (Ünal, 1980, s. 7181). Bu uygulama Büyük Selçuklu Devleti'nin güçlenmesinde etkili olmuş ise de Selçuklu idarecileri ile kavimdaşlarının arasını da açmışır. Çünkü daha devletin kuruluşu, yani Dandanakan savaşından hemen sonra, Selçuklular içinde yaşadıkları içtimai muhitin de tesiriyle, idareleri altında yaşayan yerleşik halkın tesiri altında kalmışlardır. Böylece kurdukları devlet, kurucusu olan Türkmenlerden sosyal, iktisadi ve idari bakımlardan uzaklaşarak, tedricen yerleşik halkın devleti haline gelmiştir. Sivil ve askeri idarenin teşkilinde Gazneli Devleti'nden iltica eden kumandanlar Selçuklu askeri kadrosuna, memurlar da Selçuklu Devleti'nin sivil kadrosunda görev almak suretiyle bahsi geçen devletin kuruluşunda her türlü sıkıntıyı çeken, atl1-göçebe kültürün temsilcisi Oğuzlar-Türkmenler ikinci plana itilmişlerdir. Zamanla gulam sistemine göre yetişmiş mülteci kumandanlar ve sivil idarede görev alan İranlı memurlar, Oğuzları küçümsemeye hatta tahrik etmeye başlamışlar, bu uygulama Selçuklu Devletinde "Türkmenler meselesini" doğurmuştur (Köymen, 1993, s. 159). Devlet, kuruluşundan sonra göçebelikten çıkarak, yerleşik medeniyeti temsil eden bir siyasi teşekkül haline gelmeseydi, şüphesiz (Türkmenler meselesi) diye bir mesele de ortaya çıkmayacaktı. XI. Yüzyıl için o çağın modası olarak kabul edilen bu değişiklikler, Türk sosyal ve siyasi nizamının yıkılmasında etkili olmuştur. Hemen her çağda ortaya çıkan sosyo-kültürel akımlar cemiyetlerin sarsılmasına ve hatta ani değişiklikler bazı buhranların doğmasında temel faktör olabilmektedir.

Selçuklu Devleti'nin kuruluşu sırasında, devlet halk münasebetlerinde töre hemen her bakımdan etkilidir. Çünkü halk beyi ile birlikte sevinmiş-üzülmüş, varlığa da yokluğa da ortak olmuştur. Halkın beyleri ile konuşup görüşmesi sırasında bazı formalitelere gerek duyulmamış, yani aracıya gerek kalmadan idare edilenler, idare edenlere meselelerini anlatabiliyorlard1. Ancak devletin kurulması ile yerleşik kurumlaşma düzeni başlayınca, Türkmenlerin beyleri ile konuşmaları, görüşmeleri ve dertlerini anlatmaları mümkün olmadı. Bunlardan ayrı olarak, göçebe unsurlar içinde yerleşik hayatın gelişmiş olduğu yörelerde yaylak-kışlak bulma meselesi gündeme gelmiştir. Yerleşik halk ve bilhassa

\footnotetext{
${ }^{1}$. Mehmet Altay Köymen Türkmenleri, Devlet hizmetine girenler ve girmeyenler şeklinde iki kısma ayırmıştır (Köymen, 1993, s. 159-163).
} 
idarecilerin çıkartmış oldukları formaliteler karşısında, devlet içinde aşiret-devlet anlaşması zamanla çatışma halini alacaktır.

Oğuzların başbuğlarına-beylerine saygıları ve itaatleri ise sınırsız ve karşılıksız değildi. Başbuğ da törenin gerektirdiği bazı vazifeleri yapmakla mükellefti. Bunlar yerine getirilmediği zaman saygı ve itaatte ortadan kalkıyor ve öfkeyle atlarına binen Oğuzlar, aynı aileye mensup bir başkasının etrafında toplanıyorlardı. Bunlar, Selçuklu Devleti yıkılana kadar aynı anlayışlarını sürdürdüler (Agacanov, 2013, s. 168-173).

İlk dönemde baş gösteren taht mücadelelerinde Oğuzların iddiacıların yanı başında görülmeleri bir tesadüf eseri değildi. Memlük sistemine göre yetiştirilmiş kişilerin askeri alanlarda çoğaldıkça, Oğuzların tahta muhalefet eden iddiacıları daha fazla destekledikleri görülür.

Tuğrul Bey’in üvey kardeşi İbrahim Yınal, taht için Tuğrul Bey’e isyan ettiğinde, Oğuzlar onu desteklediler. Buna karşılık İbrahim Yınal, Tuğrul Bey ile asla barışmayacağını yeminle teyit etmişti. $\mathrm{Bu}$ da Oğuzların hükümdara karşı ne kadar kırgın ve küskün olduklarını gösterir. Hatta İbrahim Yınal, Oğuzlara karşı devletin takip ettiği siyasetin, İranlı vezirlerin eseri olduğunu gösterdiği gibi, başa geçtiği takdirde devletin adeta bir göçebe Türkmen Devleti hüviyetini alacağını vadediyordu (Turan, Selçuklular Tarihi ve Türk İslam Medeniyeti, 1993, s. 136-138).

Yine Selçuklu hanedan üyesi, Selçuk Beyin büyük oğlu Arslan Yabgu'nun oğlu olan Kutalmış isyanında, Kutalmış'ın yanında elli bin Oğuz bulunuyordu (Turan, Selçuklular Tarihi ve Türk İslam Medeniyeti, 1993, s. 138-141). Alparslan memluk emirlerini mühim mevkilere çıkarırken Oğuzlardan olan beyler, Suriye'de Arap hükümdarlarının hizmetine girmeye başladılar. Fakat şunu da belirtmek lazımdır ki, Sultan Alparslan devlet kademelerinde görev alan Fars unsur ve orduda vazife yapan mülteci unsurlar ile Oğuz-Türkmen unsur arasındaki dengeye hep dikkat etmiş, bu dengenin bozulmamasına gayret etmiştir.

Daha Tuğrul Bey zamanından beri, Alparslan zamanı da dahil olmak üzere Anadolu, OğuzlarTürkmenler için gaza bölgesi idi. Oğuzlar, Anadolu'ya seferler düzenliyor, burada yağmacı boy geleneklerini uyguluyorlardı. Buradan büyük ganimetlerle geri dönüyorlardı. otlak sıkıntısı çeken Oğuzlar, bu sayede Anadolu'yu tanımış oldular. Selçuklu Devleti içinde yaşayan Müslüman halk, bunlardan zarar gördüler ve şikâyetlerini her defasında hükümdara ilettiler. Göçebe Oğuzları Hıristiyan bölgesine göndermek isteyen Alparslan, Malazgirt savaşından sonra Oğuz beylerine Anadolu'da fetihler yapıp, fethettikleri bölgeleri kendi iktâlarına vereceğini söylemiști. Bunun üzerine Oğuz beyleri Anadolu'ya fetihler yapıp göçebe Oğuzları fethedilen bu uç bölgelere yerleştirdiler. Malazgirt savaşından sonra gelişen bu süreç, kısmen de olsa Oğuzların yeni sorunlar çıkarmalarını engelledi ${ }^{2}$.

Melikşah zamanında devletteki kimlik değişimi had safhaya ulaştı. Bunun farkında olan ve zaten bu kimlik değişiminde, kendi ırkdaşlarını, akrabalarına varıncaya kadar devlet kademelerine yerleştirerek, İran devlet geleneğinde var olan devlet kurumlarını Selçuklu Devletine uygulayarak, başrolü oynayan Nizamü'l-mülk (Canatan, 2009, s. 194-220), ordudaki Memluk askerlerini alarak yerlerine Türkmenleri yerleştirdi ve Türkmenlerle devlet arasındaki soğukluğun giderilmesi için, Türkmenlerin daha büyük etki oluşturmalarına engel olmak amacı ile Sultan'a bir takım yeni usuller sundu. $\mathrm{Bu}$ usulleri "Siyasetname" adlı eserine de topladı. Nizamü'l-mülk, eserinde devletin Türkmenlerden sıkıntı çektiğine işaret ettikten sonra Türkmenlerin kalabalık olup bu devletin ilk yıllarında çok hizmet ettiklerini, zahmetlere katlandıklarını, devlette hakları olduğunu belirtiyor ve bu

\footnotetext{
2 - Oğuzların Türkmenlerin Anadolu akınları hakkında daha fazle bilgi için bkz. Mükrimin Halil Yinanç; Türkiye Tarihi Selçuklular Devri, C.I, Ekol yayınevi, ilaveli 2.Basım, Haz. Refet Yinanç, Ankara 2009, ss. 35-71; Ali Sevim, Anadolu'nun Fethi Selçuklular Dönemi, Türk Tarih kurumu, 3.Basım, Ankara 2000.
} 
sebeple hükümdarın akrabalarından ve diğer Türkmen gençlerinden bin veya daha fazlasının, memlükler gibi terbiye ederek devlette görev almalarını tavsiye ediyordu (Nizam'ül-mülk, 2009, s. 136).

Çağrı Beyin büyük oğlu Kirman Meliki Kavurd isyanında, Nizamü'l-mülk'ün, Kavurd'u Sultan Melikşah'a karșı destekleyen Türkmenlere beș yüz bin dinar gibi muazzam bir meblağ vererek bunları saf dışı etmesi, Türkmenlerin denge unsuru bir kuvvet olarak öneminin Nizamü'l-mülk tarafından bilindiğini göstermektedir.

Selçuklu Devleti'nde Divan yönetim geleneğinin teşkili ile Toy geleneği ortadan kalktı ve Türkmen beyleri, idaredeki etkinliklerini de kaybettiler. Selçuklu Devleti'nin Türkmenler meselesinin çözümü için almış olduğu tedbirler beklenen neticeyi vermemiştir. Bahsi geçen dönemde, YakınDoğu'daki hemen bütün siyasi teşekkülleri için yerleşik-göçebe mücadelesi söz konusudur.

Selçuklu Devleti, bir iç meselesi olarak kabul ettiği bu hadisenin çözümü için, Anayurttan kopup gelen Oğuz-Türkmen boylarını, aşiretlerini önce Azerbaycan'a, Malazgirt zaferinden sonra da Anadolu'ya gönderiyordu. Anadolu'nun fethi ve burada başta Anadolu Selçuklu Devleti başta olmak üzere diğer Türk Beylikleri'nin kurulmasından sonra, Türkmen meselesinin çözümü için Türkmenleri Marmara sahillerine göndermeye başlamıştır. Selçukluların batıya yürüyüşleri ile beraber sanki tabii bir göç yolu açılmış gibi Oğuzlar-Türkmenler, nüfuslarının da artması ve oldukça çok olan koyun sürülerine otlak ve su bulmak maksadı ile İslam dünyası içlerine doğru büyük bir göç hareketi başlatmışlardır. Büyük Selçuklu İmparatorluğu sınırları içerisinde ve İslam ülkelerinde kendi boy beylerinin idaresinde müstakil hareket eden bu göçebe Oğuzlar-Türkmenler çok defa Büyük Selçuklu Sultanlarını tanımıyor ve büyük Türk hakanlığı sıfatını ellerinde bulundurdukları için, eski Türk hakimiyet anlayışı gereğince çok zayıf bir siyasi bağ ile ona tabi olsalar bile, yurt bulmak ve sürüleri ile beslenmek maksadı ile İslam ülkelerini istila ediyorlar, yerli halk ile mücadelelere girişiyorlar ve neticede yağma ve kıt'ale sebep oluyorlardı (Turan, Selçuklular Tarihi ve Türk İslam Medeniyeti, 1993, s. 72). İslam ülkelerinde Türk göçü devam ediyor, İslamiyet Türkler arasında yayıldıkça da bu göçler birbirini kovalıyordu. Bu sonsuz göç ve istilalar büyük meseleler çıkarıyor ve devleti uğraştırıyordu (Turan, Selçuklular Tarihi ve Türk İslam Medeniyeti, 1993, s. 74). Bu istila ve yağmalar karşısında artık Abbasi Halifesi Kaim Biemrillah yerli halkın şikayetleri karşısında 1044 yılında devrin meşhur alimi Maverdi'yi Tuğrul Bey’e elçi olarak göndermiştir. Tuğrul Bey ise Halifeye cevabında milletinin çok olduğunu aç kalıp sağa sola yağma yapmalarına karşılık kendisinin çok fazla bir şey yapamayacağını belirtip, Halifeden anlayış bekliyordu (Turan, Selçuklular Zamanında Türkiye, 1993, s. 16-17). Nitekim ilk Büyük Selçuklu Sultanları Tuğrul Bey'den itibaren, göçebe boy ve beyleri itaate almak, eski Türk Hakimiyet anlayışına dayanan adem-i merkeziyetçi devlet anlayışı yerine, merkeziyetçi bir devlet anlayışı kurmak maksadı ile Türkmenlerin nüfuzunu kırmışlardır. Merkeziyetçi devlete doğru gelişen bu anlayış, Türkiye Selçukluları'nda ve Osmanlılar'da da devam etmiş nihayet Osmanlılar tarafından gerçekleştirilebilmiştir. Büyük Selçuklu Sultanları bir yandan Oğuzları-Türkmenleri devletlerinin kurucusu ve temeli saymışlar ve bir yandan da yurtsuz oluşları ve itaatsiz hareketleri dolayısıyla onlarla uğraşmak zorunda kalmışlardır. Nizamü'lmülk Siyasetname 'sinde "her ne kadar Türkmenlerden bıkkınlık geldi ise de, sayıları çoktur, bu devletin kuruluşunda çok hizmetleri ve emekleri geçtiği için de devlet üzerinde hakları vardır ve Sultanın akrabalarıdır" (Turan, Selçuklular Tarihi ve Türk İslam Medeniyeti, 1993, s. 75) söyleyişi ile devletin Oğuzlara bakışını çok güzel ifade etmiştir. İşte Büyük Selçuklu Sultanları, bir taraftan İslam'ın sultanı ve koruyucusu sıfatı ile İslam ülkelerini ve tebaasını bu göçebe ve yurtsuz Oğuzlar-Türkmenlerin çapullarından korumak, diğer taraftan da Türk Hakanlarının "velayet-i pederane" (babalık vasfı, görevi) sıfatı ile de aynı zamanda devletin temelini ve askeri kuvvetini teşkil eden bu soydaşlarını kondurmak, onlara yurt bulmak ve geçim imkanlarını hazırlamak gibi birbiri ile çatışan iki mesele karşısında idiler (Turan, Selçuklular Tarihi ve Türk İslam Medeniyeti, 1993, s. 72).

Tuğrul Bey, Alparslan ve Melikşah gibi ilk Büyük Selçuklu Sultanları, merkeziyetçi bir devlet vücuda getirmek ve böylece siyasi parçalanmayı önlemek maksadı ile adem-i merkeziyetçi eski Türk

\section{Turkish Studies - Historical Analysis}

Volume 14 Issue 2, 2019 
hakimiyet anlayışı ile başkaldıran asi soydaşlarını bastırmak mecburiyetinde kaldıkları halde bazı tarihçiler, Büyük Selçuklu Sultanlarının, merkezi bir idare kurmak ve Türk birliğini gerçekleştirmek yolundaki bu meşru hareketlerini "mütegallibelik" ve siyasi iktidarı ele geçirmek için eski Türk hakimiyet anlayışı gereğince hanedan haklarına dayanarak harekete geçen şehzade ve beylerin isyanlarını da "Türkmencilik" esasına göre, göçebe Oğuzların-Türkmenlerin savunucusu sanmışlar; göçebe Türkmen kütlelerinin Anadolu'ya sevki zaruretini ve Büyük Selçuklu Sultanlarının gaza ve fütuhat ülkülerini ve siyasetlerini de Sultanların göçebe Türkmenlere karşı nefreti ile izah etmek istemişler ve hatta Büyük Selçuklu ordusu içerisinde çok küçük bir birlik olan ve yabanc1 irklardan teşkil eden saray merkez muhafız kuvvetine bakarak Selçuklu ordusunun ekseriyetini Türklerden gayrı unsurların teşkil ettiği hatasına düşmüşlerdir³.

Selçuklu Devleti'nin Türkmen meselesi için aldığı ikinci tedbir, idari bakımdan olup; Türkmenleri devlete hanedana yaklaştırmak ve onları yerleşik hayata geçmeye teşvik etme şeklindedir. Selçuklu Devleti'nin ünlü Veziri Nizamülmülk, Türkmenler meselesinin devlet için önemini kavramış olduğundan yerleşik-göçebe çekişmesinin halledilmesi için daha önce de belirttiğimiz gibi tedbirler almıştır. Fakat Selçuklu devlet adamlarının ve hatta Sultanlarının bu konuda almış olduğu tedbirler yetersiz kalmıştır. Çünkü Oğuzlar-Türkmenler kendilerini doğrudan doğruya Sultan'a bağli sayıyorlar ve devletin kendi devletleri olduğuna inanıyorlardı. Meselenin çözülmemesinin esas sebebi de bu olmalıdır (Yuval1, 1992, s. 9).

Tuğrul Bey, Alparslan ve Melikşah zamanında devam eden bu mesele, fetret devrinde de devam etmiş ve Büyük Selçuklu Devleti'nin son hükümdarı, Melikşah'ın, Berkyaruk ve Muhammed Tapar'dan sonra tahta geçen üçüncü oğlu Sancar devrinde devletin esas meselesi olarak, devletin dağılmasında etkili olmuştur; Sancar Belh ve Huttelan yöresinde yurt tutan Oğuzların Üçok ve Bozok koluna mensup Türkmenleri devlet hizmetine almayıp onları "raiyyet", halk zümresinden sayıyordu. Kırk bin çadırdan oluşan bu insanların vergileri Sultanın haslarına dahil edilmiş ve yılda yirmi dört bin koyun idi. Belh valisi Kamaç, Sultanın bilgisi dahilinde Türkmenlere bölgeyi terk etmelerini bildirdi. Oğuzlar önce valiye sonra da Sultana müracaat ederek, ödedikleri vergi miktarının arttırılmasını fakat yurtlarından çıkartılmamalarını istediler. Vali Kamaç, aniden Oğuzlar üzerine saldırdı ise de mağlup oldu ve Oğuzlar parlak bir zafer kazandılar (Ayan, 2007, s. 23). Sultan Sancar bu yenilginin intikamını almak maksadıyla büyük bir kuvvetle onların üzerine yürüdü. Oğuzlar Sultan'a gönderdikleri elçiler vasıtasıyla "biz Sultana daima sadık kullar idik, Kamaç ocağımıza kastetti, onunla çoluk çocuğumuz için savaştık, 100.000 dinar ile 1000 Türk gencini köle verelim de Sultanımız bizi bağışlasın" (Turan, Selçuklular Tarihi ve Türk İslam Medeniyeti, 1993, s. 247), (Köymen, 1993, s. 300), (Sümer, 1992, s. 103-104) dediler. Oğuzların verilecek köleleri Kamaci olarak nitelemeleri burada meseleyi, kendileri ile devlet arasında değil, kendileri ile Kamaç arasındaki bir mesele olarak gördüklerini ortaya koymaktadır. Sultan Sancar yerli emirlerin tesiriyle bu isteği kabul etmedi. Sancar'ın kuvvetlerinin yaklaşması üzerine Oğuzlar kadın ve çocuklarını önlerine katıp Sultan'dan af dilediler. İlk vergi tekliflerine ilave olarak her haneden yedi batman gümüş vergi vermeyi taahhüt ettilerse de Sancar, yine emirlerinin ısrarı ile bu teklifi de reddetti (Sümer, 1992, s. 105), (Ayan, 2007, s. 39). Çoluk çocuklarıyla Sultana yalvarmalarının sonuçsuz kaldığını gören Oğuzlar da korkunun yerini kin ve nefret aldı ve Mart-Nisan 1153 tarihinde Sancar ve ordusunu mağlup, Sultan başta olmak üzere birçok devlet adamını esir aldılar (İbnü'lesir, 2016, s. 157). Bu başarıdan sonra Oğuzlar Belh, Merv ve yöredeki bazı şehirleri yağmaladılar. Sultanı da kendi sultanları sayarak, bağlılıklarını bildirdiler. Ancak Sultan Oğuzların elinde tutsak ve kaçırılma teşebbüsünden sonra, kaçmaması için onu demirden bir kafese koymuşlardı (İbnü'lesir, 2016, s. 157159).

\footnotetext{
${ }^{3}$ Bu hatalı görüşler için bkz. Zeki Velidi Togan, Umumi türk Tarihine Giriş, C.I, İ.Ü. Edebiyat Fakültesi Yayını, İstanbul, 1970, 2.basım, s.194 vd.; ayrıca Osman Turan, Selçuklular Tarihi ve Türk İslam Medeniyeti, s.75.
} 
Sencer'e hürmet ve tazimde bulunmaları, Oğuzların Türk devlet geleneğinde hakana olan saygılarından ileri geliyordu. Oğuzlar, Sencer'e başlangıçta hükümdarları gibi davrandılar. Fakat Oğuz şefi Bahtiyar'ın Merv'e vardıklarında Merv'in hassa iktâlarından kendisine verilmesi istemesi, Sencer'in bu iktâların gelirinin hazineyi hassa adına toplandığını belirtmesi üzerine, Oğuzların bu cevabı kahkahalarla karşılamaları, Sencer' in esaretinin farkına varmasına sebep oldu.

Bu esnada Nişabur'a kaçmış olan Sultan Sencer'in emirleri, orada Sencer'in yeğeni olan, Sultan Muhammed Tapar'ın oğlu Süleymanşah'ı hükümdar yaptılar. Süleymanşah, Merv üzerine yürüdü ise de askerleri, Oğuzlar'ı görünce kaçtılar. Onları kovalayan Oğuzlar, yolları üzerindeki Tus'u yağmaladıktan sonra Nişabur'a geldiler. (1153) Bu şehir de Merv gibi Oğuzlar tarafından korkunç bir şekilde yağmalandı. Bu yağmalar esnasında birçok insan öldü. Bütün bu yürüyüş esnasında Sencer de Oğuzların yanında demir bir kafes içinde idi.

Sencer'in dağılmış olan emirleri, Süleyman Şah'ın başarısız olmasıyla toplanarak Karahanlı Muhammet Han'ın oğlu Mahmud'u hükümdar seçtiler. Mahmud, ilk iş olarak Oğuz meselesini halletmeye çalıştı. Bu sırada Herat'ı kuşatmakta olan Oğuzlar'ın üzerine yürüdü. İki taraf arasında birçok savaşlar oldu. Bu savaşların Çoğunu Oğuzlar kazandı. Mahmud, Oğuzlara karşı yaptığı muharebelerde pek başarılı olamasa da ilerlemelerini durdurdu.

Oğuzlar, Temmuz-Ağustos 1155'de Merv'e döndüler ve oradan Mahmud'a elçiler göndererek onunla barış yaptılar. Mahmud, Süleymanşah gibi zayıf bir şahsiyet olup, bütün kudret Selçuklu Emirlerinden Müeyyed Ay-Aba'nın elinde idi. Müeyyed Ay-Aba, Nişabur'dan başka Tus, Nesa ve Abiverd'i de ele geçirdi. Oğuzların elindeki yerler ise, Belh, Merv ve Serahs bölgeleri idi. Mahmud Han ile barışın yapılmasından sonra Sencer'in emirleri Merv'e gidip, onu ziyaret edebiliyorlardı.

Sultan Mahmud, yanlış bir siyaset olarak Harzemşah Atsız'dan yardım istedi. Sencer'in sultanlığını şeklen kabul etmiş olan Mahmud'un, Sencer'i kurtarmayıp sadece Atsız'dan yardım istemesi, bu yardım isteğini firsat bilen Atsız'ın Horasan'1 ele geçirmesi üzerine Müeyyed Ay-Aba siyasetini değiştirdi. Bazı kumandanları yanına topladı ve Nişabur, Tus, Damgan’1 zaptetti.

Ekim/Kasım 1156'da Müeyyed Ay-Aba, nöbetçi Oğuzları kandırarak Sencer'i esaretten kurtarıp Belh'ten Tirmiz'e kaçırdı. Sencer bir müddet burada kaldıktan sonra Merv'e geldi. Belh bölgesinde bulunan Oğuzlar, Sencer'in ne yapacağını merak ve kaygıyla beklediler. Sencer, yetmiş iki yaşında, ruhen çökmüş, hazinesi boş, ülkesi harap, askerleri dağılmış bir şekilde hiçbir harekette bulunmadan kurtuluşundan yedi ay sonra Merv'de öldü (26 Nisan 1157) (Ayan, 2007, s. 34).

Oğuz isyanının en büyük sonucu, Sencer'in Oğuzların eline esir düşmesi ve bu şekilde Büyük Selçuklu İmparatorluğunun fiilen sona ermesi oldu. Oğuzların mevcut düzeni korumak ve diş müdahaleleri önlemek için Sencer'i korumayı ve onu hükümdar gibi göstermeyi siyasetlerine uygun buldukları görülür. Kendi öz kavmine karşı ilgisiz olan Selçuklu Sultanları'nın ihmali, devletin kurucusu ve as1l sahibi olan Oğuz Türklerini isyana mecbur etmiştir.

Sencer'in ölümü Oğuzları rahatlatmıştı. Oğuzlar, Sencer'in ölümü üzerine Sultan Mahmud'la anlaşma yollarını aradılar. Sultan Mahmud'dan hükümdarları olmasını istediler. Böylelikle Oğuzların hâkimiyeti meşru kılınacaktı. Yine, başlarına geçecek hükümdar, Oğuz beyleri arasındaki anlaşmazlıkları da giderecekti. Mahmud, bu teklifi kabul ederek Oğuzların başına hükümdar oldu (17 Mayıs 1159).

Fakat bu hükümdarlığı Ay-Aba kabul etmeyerek Oğuzlara karşı mücadelesini sürdürdü. Ağustos 1161 tarihinde Mahmud Han'ın başında bulunduğu Oğuz ordusu ile Ay - Aba'nın emrindeki ordu arasında yapılan savaşta Mahmud kaçarak Oğuzları yalnız bıraktı ve Oğuzların bir Türk devleti kurma amaçları gerçekleşemeden bitti. Ay-Aba'ya gelince, bu başarılar, Ay-Aba'nın cüretini arttırdı. 
Ay-aba, Oğuzları tamamen ortadan kaldırmak için yeni bir sefer düzenledi. Fakat beklediği olmadı. Oğuzlar karşısında ağır bir hezimete uğradı.

Oğuzlar, Gur hükümdarıyla yaptıkları mücadeleler sonucu bir ara Gazne'yi de ele geçirdiler. Böylelikle sınırlarının içine Merv, Serah, Belh, Nesa, Abiverd ve Gazne toprakları bulunuyordu.

Oğuzlar, 1164-1165 yılından itibaren siyasi önemlerini kaybetmeye ve dağılmaya başladılar. Bu durum, onların müşterek bir otoriteye, hükümdara sahip olmamalarından kaynaklanmıştır. Karahıtaylar'ın Merv'i ele geçirip Serahs'a akınlar yapmaları ve bölgedeki güçlerini arttırmaları üzerine Oğuzlar tamamen dağgldılar.

\section{SONUÇ}

Büyük Selçuklu Devleti, Türklerin tarihte kurmuş olduğu Hunlar, Göktürklerden ve Uygurlardan sonra dördüncü büyük imparatorluğudur, İslami dönemin ise ilk büyük imparatorluğudur. $\mathrm{Bu}$ devlet ve devleti kuran Selçuk Bey ve ailesi, kuruluşundan itibaren sırtını kendi içinden çıktığı ırkdaşlarına yani Oğuzlar-Türkmenlere yaslamış, onların sayesinde mücadele ederek, onların yardımlarıyla çok geniş coğrafyaları ele geçirmiş ve devletlerini kurmuşlardır. Fakat batıya İslam dünyası içlerine doğru ilerlemenin getirdiği siyasi, idari ve sosyal gelişmeler, şartlar ve gereklilikler onları, devlet yönetiminde farklı uygulamalara gitmeye zorlamış, dolayısıyla kurdukları devletin genişlemesi ile beraber yönetimde bürokrasi unsuru artan bir biçimde yer almaya başlamıştır. Bu durum devletin kurucu unsuru olan Oğuzların-Türkmenlerin sadece askerlik alanına münhasır kalmalarını ve devlet yönetiminden uzaklaştırılmaları sonucunu beraberinde getirmiştir, onlar ikinci plana düşmüşler, İranlı Fars bürokratlar Nizamü'l--mülk ile beraber çok daha etkin bir konuma gelmişlerdir. Kurdukları devlete ve Sultanlarına küsen, kırılan ve yönetimden uzaklaştırılan Oğuz-Türkmen boyları, bunun acısını kurdukları devlete isyan ederek ve nihayetinde yıkarak göstermişlerdir.

\section{KAYNAKÇA}

Agacanov, S. (2013). Oğuzlar. (E.Necef-A.Berdiyev, Çev.) İstanbul: Selenge yayınları.

Armenius Vambery. (2004). Skeches of Central Asia. London.

Asım, N. (2015). Türk Tarihi (Osmanlıca Tipkı basım). İstanbul: Pergole.

Ayan, E. (2007). Büyük Selçuklu İmparatorluğunda Ŏguz İsyanı. İstanbul: Kitabevi yayınları.

Canatan, K. (2009, Fall). Geleneksel Siyaset ve Devlet Felsefesinin Bir Yorumu Olarak "Siyasetname" - Büyük Devlet Adamı Nizamü'l Mülk'ün Devlet ve Siyaset Anlayışı Üzerine, Volume 4/7. ANKARA, TURKEY: Turkish Studies International Periodical For the Languages, Literature and History of Turkish or Turkic. doi:10.7827/TurkishStudies.905

Demir, M. (2004). Büyük Selçuklular Tarihi. Adapazarı: Sakarya Yayıncılık.

Deny, J. (2012). Türk Dil Bilgisi. (Ahmet Benzer, Çev.) Kabalcı Yayınevi.

İbnü'lesir. (2016). El- Kamil fi't- Tarih (Cilt XI). (A. Özaydın, Çev.) İstanbul.

Kafesoğlu, İ. (Eylül 2014,). Selçuklular ve selçuklu Tarihi Üzerine Araştırmalar. İstanbul: Ötüken Yayınevi.

Kaşgarlı Mahmud. (1988). Divanu Lügat-it-Türk (Cilt III). (B. Atalay, Çev.) Ankara: Atatürk Dil ve Tarih yüksek Kurumu.

Koca, S. (2011). Selçuklu Devri Türk Tarihinin Temel Meseleleri. Ankara: Berikan Yayınevi. 
Köymen, M. A. (1993). Selçuklu Devri Türk Tarihi (2 b.). Ankara: Türk Tarih Kurumu.

Nizam'ül-mülk. (2009). Siyasetname. İstanbul: Antik Yayınları.

Ögel, B. (1971). Türk Kültürünün Gelişme Çağları (Cilt II). İstanbul: Kültür Bakanlığı.

Ögel, B. (1982). Türklerde Devlet Anlayışı (XIII. Yüzyıl Sonlarına Kadar). Ankara.

Reşidü'd-din Fazlullah. (2016). Cami'ü-t Tevarih. (E. Göksu, \& H. Güneş, Çev.) İstanbul: Bilge Kültür Sanat Yayınları.

Rızayev, F. (2010). Selçuklu Oğuzlarının Tarihine, Onların Yayılma Alanlarına ve "Oğuz" Sözcügünün Etimolojik Yorumuna Yeni Bakış. I.Uluslararası Selçuklu Sempozyumu, Selçuklu Siyasi Tarihi (Bildiriler) (s. 213-222). Kayseri: Türk Tarih Kurumu.

Sümer, F. (1992). Oğuzlar (Türkmenler) Tarihleri, Boy, Teşkilatları, Destanları. İstanbul: Türk Dünyas1 Araştırmaları Vakfi.

Turan, O. (1993). Selçuklular Tarihi ve Türk İslam Medeniyeti (4 b.). İstanbul: Boğaziçi Yayınları.

Turan, O. (1993). Selçuklular Zamanında Türkiye. İstanbul: Boğaziçi.

Ünal, O. (1980). Horasan'dan Aanadolu'ya Türkiye Tarihine Giriş. Ankara: Töre-Devlet yayınevi.

Yinanç, M. (2009). Türkiye Tarihi Selçuklular Devri (İlaveli İkinci Baskı b., Cilt I). (R. Yinanç, Dü.) Ankara: Ekol yayınevi.

Yuvalı, A. (1992). Türklerde Devlet-Aşiret Münasebetleri. Dadaloğlu Vakfi(3), 5-12. 